\title{
Gluteus maximus and semitendinosus activation during active prone hip extension exercises
}

\author{
Ativação do glúteo máximo e semitendinoso durante exercícios \\ de extensão do quadril em prono
}

\author{
Sakamoto ACL', Teixeira-Salmela LF², Rodrigues de Paula F², Guimarães $\mathrm{CQ}^{2}$, Faria CDCM²
}

\begin{abstract}
Background: Gluteus maximus strengthening exercises are employed in clinical practice as options for the treatment of low back and sacroiliac disorders. However, no studies were found that investigated which were the best exercises to activate this muscle and justify its employment in physical therapy practice. Objective: To quantify the electromyographic (EMG) activity of the gluteus maximus and semitendinosus muscles during four modalities of therapeutic exercises. Methods: Thirty-one participants (16 men, 15 women) were selected. The EMG activities of the gluteus maximus and semitendinosus was recorded and quantified while the participants performed four modalities of therapeutic exercises, involving active prone hip extension in four positions: knee extension (KE), knee flexion (KF), lateral hip rotation and knee extension (LHRKE), and lateral hip rotation and knee flexion (LHR-KF). Results: Repeated-measures ANOVAs showed that the addition of KF or LHR increased gluteus maximus activity, whereas, KE decreased the activation of this muscle. In contrast, the exercises performed with KE increased semitendinosus activity. Conclusions: Exercises performed with KF or LHR, or a combination of the two, may be effective choices for gluteus maximus strengthening, however both KF and LHR decreased semitendinosus activity. The exercises performed with KE appeared to be an acceptable choice for semitendinosus activation.
\end{abstract}

Key words: gluteus maximus; semitendinosus; therapeutic exercises; electromyography.

\section{Resumo}

Contextualização: Exercícios para fortalecimento do glúteo máximo são empregados na prática clínica para tratamento de disfunções da coluna lombar e sacroilíaca. Entretanto, não foram encontrados estudos que investigaram os melhores exercícios para ativar esse músculo de forma a justificar a sua utilização na prática fisioterapêutica. Objetivo: Quantificar a atividade eletromiográgica (EMG) dos músculos glúteo máximo e semitendinoso durante quatro modalidades de exercícios terapêuticos. Métodos: Trinta e um participantes (16 homens, 15 mulheres) foram selecionados. A atividade EMG do glúteo máximo e semitendinoso foi registrada e quantificada enquanto os indivíduos realizaram quatro modalidades de exercícios terapêuticos envolvendo extensão ativa do quadril em prono em quatro posições: joelho em extensão, joelho em flexão, rotação lateral do quadril e extensão do joelho e rotação lateral do quadril e flexão do joelho. Resultados: ANOVA medidas repetidas revelou que a adição de flexão do joelho ou rotação lateral do quadril aumentou a atividade do glúteo máximo, enquanto os exercícios realizados com extensão do joelho resultaram na redução da sua ativação. Por outro lado, os exercícios realizados com extensão do joelho aumentaram a atividade do semitendinoso. Conclusões: Os exercícios realizados com flexão de joelho e/ou rotação lateral do quadril demonstraram ser opções efetivas para ativação do glúteo máximo, mas resultaram em redução da atividade do semitendinoso. Os exercícios realizados com extensão do joelho demonstraram ser uma boa opção para ativar o semitendinoso.

Palavras-chave: glúteo máximo; semitendinoso; exercícios terapêuticos; eletromiografia

Received: 27/09/2008 - Revised: 19/01/2009 - Accepted: 03/02/2009

\footnotetext{
Department of Physical Therapy, Centro Universitário de Belo Horizonte (UniBH), Belo Horizonte (MG), Brazil Department of Physical Therapy, Universidade Federal de Minas Gerais (UFMG), Belo Horizonte (MG), Brazil Correspondence to: Luci Fuscaldi Teixeira-Salmela, Department of Physical Therapy, Universidade Federal de Minas Gerais, Avenida Antônio Carlos, 6627, Campus Pampulha, CEP 31270010, Belo Horizonte (MG), Brazil, e-mail: Ifts@ufmg.br
} 


\section{Introduction $: \therefore$.}

Imbalances of the lumbar spine and pelvic stabilizing muscles have been shown to be associated with the development of low back pain and, currently, emphasis has been put on the importance of achieving coordinated activity between all muscles within a balanced muscular system for the prevention and treatment of lumbar and pelvic disorders ${ }^{1-7}$. The sacroiliac joints work as shock absorbers during early stance in gait and also transmit ground reaction forces from the lower limbs to the trunk $k^{8-10}$. The joint surfaces are parallel to the line of weight transmission, resulting in a significant shear stresses during gait or upon one leg stance activities ${ }^{8,9}$.

It has been proposed that the stability of the pelvis depends on both the form and force closures ${ }^{10}$. The form closure depends primarily upon the bone structures of the pelvis and the joint surfaces which allow the sacroiliac joint to resist shear forces, whereas, force closure refers to additional compressive forces necessary for maintaining the stability of the sacroiliac joint. The force closure is a dynamic process performed by the muscular system which depends upon the integrity of the ligamentous and fascial structures of the pelvis ${ }^{9,10}$ and can also be affected by the muscles which directly compress the joint or by the tensioning of the sacrotuberous or the long dorsal ligaments ${ }^{8,9,11}$. The gluteus maximus, due to its perpendicular aligned fibers, is important for providing effective load transmission through the sacroiliac joint, contributing to the force closure $\mathrm{r}^{6,8,9,12}$. This function leads to effective compression of the sacroiliac joints and avoids shearing forces through its attachments with the lumbar paraspinal muscles, thoracolumbar fascia and biceps femoris muscle via the sacrotuberal ligament ${ }^{6,13,14}$.

Previous studies have identified that the gluteus maximus can significantly influence sacroiliac joint stability and its weakness has been found to be associated with low back pain ${ }^{5,12,14}$. This has a major functional importance in the early stance of gait by compressing the sacroiliac joint to provide stability ${ }^{8}$. Its inappropriate activation in gait is thought to be a cause of low back pain. This results in a failed load transfer system, whereas the hamstrings has been shown to have an early onset in patients with sacroiliac joint disorders, which is thought to be a compensation for weaknesses of the gluteus maximus ${ }^{2,8}$.

Gluteus maximus strengthening exercises have been used in clinical practice for the treatment of low back and sacroiliac disorders; however, no studies were found which investigated which are the best exercises to activate this muscle and justify their employment in physical therapy practice. Several exercises have been used in physical therapy to strengthen the gluteus maximus; however, there is no consensus regarding which exercises result in its optimal activation. Active prone hip extension exercises with the knee in extension could, in theory, activate the gluteus maximus and hamstring muscles, which are the prime movers of this type of extension, as well as to activate the erector spinae which acts by stabilizing the lumbar spine and the pelvis.

A commonly employed exercise to optimize gluteus maximus activation is the active prone hip extension with knee flexion, because this position leads to the active insufficiency of the hamstring muscles. However, this position leads to decreased biomechanical resistance and, consequently, to a possible decreases in the gluteus maximus activation. The superior fibers of the gluteus maximus have their attachments in the iliotibial band and the inferior fibers in the gluteus tuberosity, which makes it a stronger lateral hip rotator. Therefore, these actions can be combined with hip extension to maximize the recruitment of this muscle ${ }^{15}$. No studies were found which demonstrated that the addition of knee flexion and/or its association with lateral hip rotation would increase electromyography (EMG) activity of the gluteus maximus muscle.

Therefore, the purpose of this study was to quantify the activation of the gluteus maximus and semitendinosus muscles and to asssess at which point in the range of motion (ROM) its peak of activity occurred with healthy young individuals during four modalities of therapeutic exercises often employed in clinical practice.

\section{Methods::}

\section{Participants}

Thirty-one healthy, young participants (16 men and 15 women) were recruited from the community. Inclusion criteria were the absence of shortening of the hip flexors, determined by a negative Thomas test ${ }^{16}$, no complaints of pain, no histories of surgery of the lumbar spine or hip, and other limitations which could prevent data collection.

\section{Instrumentation}

The activation of the gluteus maximus and semitendinosus muscles were assessed by EMG (MP150WSW, Biopac Systems, Inc., Santa Barbara, CA, USA). This device has two amplifiers with input impedance of $2 \mathrm{M} \Omega$ and $C M R R$ of $1000 \mathrm{M} \Omega$ and allowed data acquisition at frequencies from 10 to $1000 \mathrm{~Hz}$. Data were collected at $1000 \mathrm{~Hz}$. with TSD of 150 (Ag/AgCl) bipolar active surface electrodes with a $13.5 \mathrm{~cm}$ diameter and an impedance of $100 \mathrm{M} \Omega$. The amplifier outputs were connected to a computer (CPU Intel Q6600, 2 GB RAM and 250 GB HD).

Displacement measurements were detected by a motion capture system ProReflex MCU Qualisys (QUALISYS MEDICAL 
AB, Gothenburg, Sweden), with capture rates of $120 \mathrm{~Hz}$ and digital cameras (MCU 120), equipped with a set of infra-red light emitters which were reflected by spherical passive markers of $12 \mathrm{~mm}$ in diameter and attached to specific anatomical locations. Procedures for the linearization and calibration were performed according to the instructions in the manufacturer's manual. Three cameras were employed to capture the images and positioned so that all markers were registered during all investigated movements.

\section{Procedures}

Before data collection, participants were informed about the objectives of the study and were invited to sign a consent form previously approved by the Ethics Review Board from the Universidade Federal de Minas Gerais (number 172/04). Demographic data were collected on all participants to document ages and other clinically relevant information. To obtain the EMG data, subjects were instructed to lie in a prone position and passive markers were placed over the iliac crest, anterior superior iliac spine, posterior superior iliac spine, greater trochanter, middle point of the thigh and the lateral epicondyle of the femur of the evaluated lower limb. All markers were $12 \mathrm{~mm}$ in diameter with the exception of the one placed over the anterior superior iliac spine, that was $5 \mathrm{~mm}$ to avoid discomfort during exercises.

Surface electrodes were placed in pairs and parallel to the muscle fibers ${ }^{17}$. For the gluteus maximus, the electrodes were placed at the midpoint of a line running from the last sacral vertebrae to the greater trochanter. For the semitendinosus, they were medially placed at middistance between the gluteal fold and the knee joint ${ }^{17}$. The inter-electrode spacing was $2 \mathrm{~cm}$ from their centers. The reference electrode was placed over the lateral malleolus. Skin preparation included shaving, rubbing and cleaning with alcohol.

The verification of the signal quality was carried out for each muscle, using a maximum voluntary isometric contraction (MVIC) to normalize the amount of EMG activity for each muscle between the exercises. All of the procedures for the EMG recording followed the recommendations of the International Society of Electromyography and Kinesiology ${ }^{18}$. Manual resistance was gradually applied up to the maximum level, and then held for five seconds. Each MVIC was repeated three times, with two minute rest intervals. Proper electrode placements were also confirmed by observing the EMG signal amplitude during the manual muscle tests. MVIC measurements of the gluteus maximus were carried out with the hip in maximum extension and with $90^{\circ}$ of knee flexion for the semitendinosus muscle. Worrell et al. ${ }^{19}$ recommended that the normalizing contractions should be performed at joint angles close to that assumed during the activity of interest. During the MVIC measures, verbal encouragements were given to the participants to reach maximal muscular activation. After this procedure, a 20-minute rest interval was allowed and then, the participants were instructed to lie in a prone position for familiarization with the exercises.

A light was placed in front of the subjects and they were instructed to begin the required movements at their natural speed when the signal was turned off. EMG activities of the gluteus maximus and semitendinosus muscles were obtained as the subjects performed the four modalities of the therapeutic exercises, which involved active prone hip extension in four positions (Figure 1): with knee extension (KE), knee flexion (KF), lateral hip rotation and knee extension (LHR-KE), and lateral hip rotation and knee flexion (LHR-KF).

As demonstrated in Figure 1B, a wooden device was employed to position the subjects' legs and to guarantee relaxation during the performance of exercises involving KF. Therefore, the only performed movements were hip extension and the KF and LHR were only used for positioning, which was maintained during hip extension.

All exercises were randomly assigned and three trials were obtained for each modality with a two minute rest period between trials. The mean of the three trials for each exercise was used for analyses. The initiation of the movement was determined by changes in the angular displacement of the rigid segment, determined by the markers 1,2 , and 3 related to the pelvis and 4, 5, and 6 related to the thigh (Figure 1A), as obtained from the motion data collection system. The end of the movement was determined with the reverse process. The time to perform the exercises was normalized by $100 \%$ and each $5 \%$ interval was calculated. Thus, it was possible to determine the phase where the highest muscular activation occurred. A trigger mechanism was used to synchronize the EMG and the motion capture system data, after assuring EMG silence.

\section{Data processing}

The motion capture system data processing was performed using the Qualisys Track Manager 1.6.0.X software and latter the data were exported to the MATLAB ${ }^{\circledR}$ for analyses. Joint angles were calculated only in the sagittal plane, using the $\mathrm{X}$ and $\mathrm{Z}$ coordinates. Two straight lines from the pelvic and lower limb segments were traced and the prolongation of these lines provided information regarding the joint angle ${ }^{20}$.

EMG data processing was performed using the software AcqKnowledge. The EMG signals were full wave rectified and low-pass and high-pass filtered with cut-off frequencies of 500 and $10 \mathrm{~Hz}$, respectively. Root mean squares were used to quantify the EMG activities and the average values of the EMG activities during the exercises were used to normalize the signals. The quantification of the muscular activity and ROM 


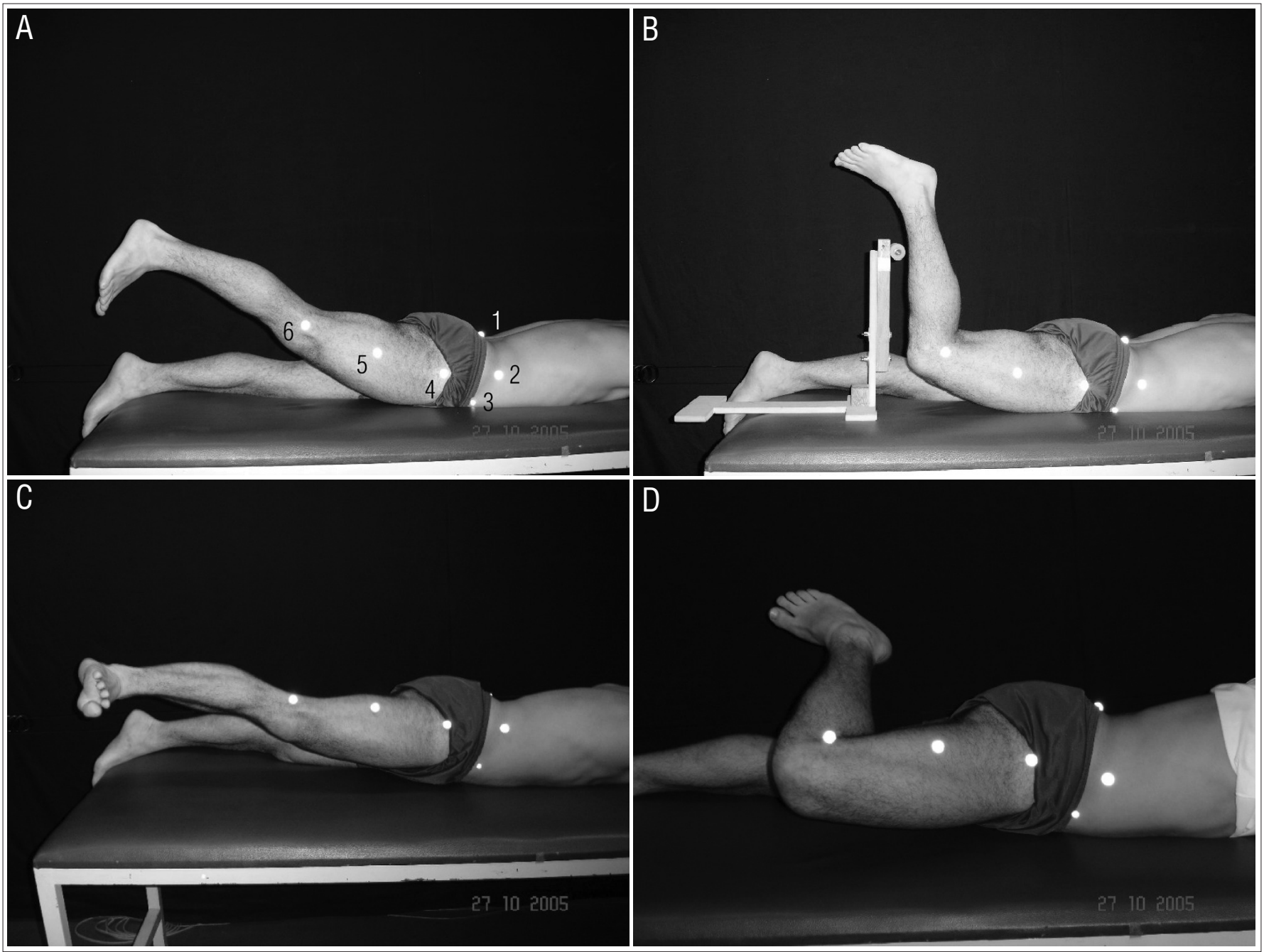

Figure 1. Active prone hip extension exercises: With knee extension (A); knee flexion (B); lateral hip rotation and knee extension (C); and lateral hip rotation and knee flexion (D).

corresponding to the peak of activity were calculated by specific procedures developed in MATLAB ${ }^{\circledR 20}$.

\section{Data analyses}

Descriptive statistics and tests for normality and homogeneity of variance were calculated for all outcome variables with the SPSS 13.0 for Windows (SPSS, Inc., Chicago, IL.). Repeatedmeasures ANOVAs, followed by planned contrasts were used to investigate differences in muscular activation for the four modalities of exercise, with a significance level of $\alpha<0.05$.

\section{Results $:: \therefore$}

\section{Subject characteristics}

Thirty-one volunteers participated in the study, with ages ranging from 20 to 36 years (mean \pm SD, 24.5 \pm 3.5 years), height from 150 to $184 \mathrm{~cm}(170 \pm 9 \mathrm{~cm})$, body mass from 46 to $90 \mathrm{~kg}$ $(66.89 \pm 11.89 \mathrm{~kg})$; and body mass indices of $22.09 \pm 2.22 \mathrm{~kg} / \mathrm{m}^{2}$ for women and $23.75 \pm 3.49 \mathrm{~kg} / \mathrm{m}^{2}$ for men. Because of technical problems with MATLAB in the analysis of some motion analysis system files, data from two subjects (one man and one woman) were excluded for analyses for the exercises performed with the KE and KF and one for the LHR-KE.

\section{Muscular activity}

As illustrated in Figure 2, the gluteus maximus showed the highest activity levels during the exercises performed with KF (23.1 $\pm 21.2 \%)$, followed by those associated with LHR with both KE $(22.5 \pm 10.3 \%)$, and KF $(21.2 \pm 11.9 \%)$. The exercises performed with $\mathrm{KE}$ were the ones which the gluteus maximus showed the lowest levels of EMG activity (12.66 \pm 8.57$)$. In addition, significant differences were found only for exercises performed with $\mathrm{KE}$, when compared to those with $\mathrm{KF}$ ( $\mathrm{p}=0.04$; power $=0.54$ ), LHR-KE $(\mathrm{p}<0.0001$; power $=0.99)$, and LHRKF $(\mathrm{p}=0.013$; power $=0.72)$. 
These findings indicated that the addition of KF and/or LHR were effective in activating the gluteus maximus muscle.

In contrast, the exercises performed with $\mathrm{KE}$ were the ones in which the semitendinosus muscle showed the highest EMG activity level $(22.02 \pm 16.20 \%$; $\mathrm{p}=0.006)$. ANOVA also demonstrated significant differences in semitendinosus activity between all exercises $(\mathrm{p}<0.05)$. As shown in Figure 2, the semitendinosus muscle showed the highest EMG activity levels during the exercises performed with $\mathrm{KE}$, followed by those with $\mathrm{KF}$

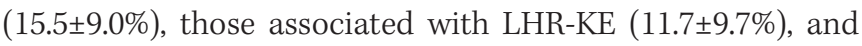
LHR-KF (5.9 $\pm 3.4 \%)$.

\section{Percentages of the movement cycle corresponding to the peak of EMG activity}

The mean ROM and the percentages of the movement cycle corresponding to the peaks of the EMG for the gluteus maximus and semitendinosus muscles are displayed in Table 1. When the ROM was analyzed alone, significant differences were found between the ROM corresponding to the peak of the gluteus maximus and semitendinosus activities for the exercises performed with KF and KE, 10 compared to those associated with LHR $(\mathrm{p}<0.05$; power $=0.90)$, indicating that when the hip was laterally rotated, the peak of activity occurred in a lower ROM (Table 1).

Significant differences were found for the peaks of activity of the gluteus maximus and semitendinosus in relation to the percentages of the movement cycle, when compared to the exercises performed with $\mathrm{KE}$ and $\mathrm{KF}$ ( $\mathrm{p}=0.02$; power $=0.61$ ) and those performed with LHR-KE and LHR-KF ( $p=0.013$; power $=0.68$ ). This indicated that when the knee was flexed, the peak of activity of the hip extensors occurred earlier during this movement cycle.

Regarding ROM, differences were also observed for the peak of activity of the gluteus maximus and semitendinosus muscles during the exercises performed with KE when compared to those associated with LHR with both KE and KF $(p<0.0001$; power=0.99) and the percentages of the movement cycle ( $p=0.013$ and $<0.0001$; power $=0.73$ and 0.97 ). This showed that during the exercises performed with $\mathrm{KE}$, the peak of the hip extensors occurred at the end of the movements (Table 1). The peak of the semitendinosus activities occurred earlier during the LHR-KF exercises when both the ROM $(\mathrm{p}<0.001)$ and the percentages of the movement cycle were considered $(p<0.0001)$, compared to the other modalities.

\section{Discussion $: \because$.}

The current study investigated the amounts of EMG activity of the hip extensor muscles during the four modalities of

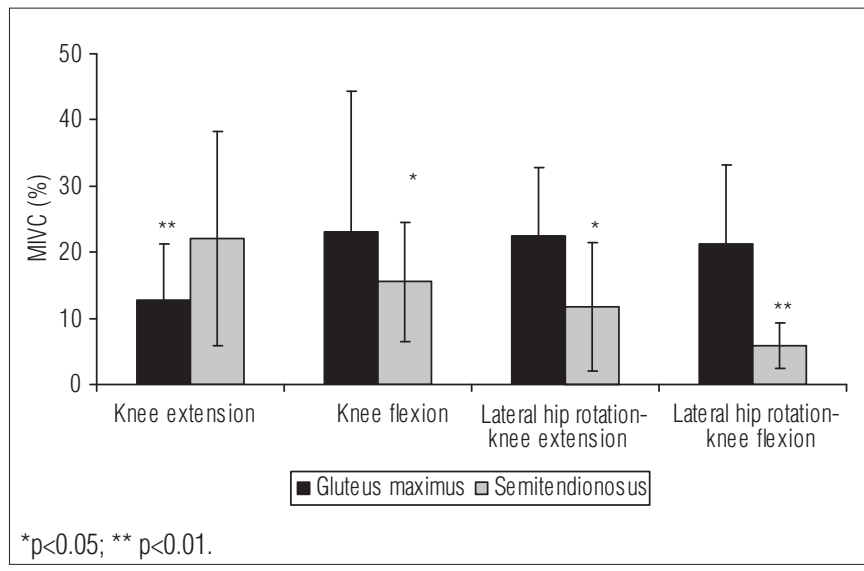

Figure 2. Means $\pm S D$ of the electromyographic signal amplitude of the gluteus maximus and semitendinosus muscles during the four modalities of therapeutic exercises.

Table 1. Means $\pm S D$ for the range of motion (degrees) and percentage of the movement cycle corresponding to the peak of EMG activity of the gluteus maximus and semitendinosus muscles during four modalities of active prone hip extension exercises $(\mathrm{n}=30)$.

\begin{tabular}{lcc}
\hline Exercise & Gluteus Maximus & Semitendinosus \\
\hline Range of motion $\left(^{\circ}\right)$ & & \\
\hline Knee extension $(\mathrm{KE})$ & $17.0 \pm 4.2 \dagger$ & $16.3 \pm 4.3 \dagger$ \\
\hline Knee flexion $(\mathrm{KF})$ & $15.8 \pm 4.8 \ddagger$ & $14.7 \pm 5.2 \ddagger$ \\
\hline $\begin{array}{l}\text { Lateral hip rotation-knee extension } \\
\text { (LHR-KE) }\end{array}$ & $12.4 \pm 4.9$ & $10.6 \pm 5.4$ \\
\hline $\begin{array}{l}\text { Lateral hip rotation - knee flexion } \\
(\text { LHR-KF) }\end{array}$ & $12.1 \pm 5.7$ & $8 \pm 5.5$ \\
\hline
\end{tabular}

\begin{tabular}{lll}
\hline Movement cycle $(\%)$ & & \\
\hline Knee extension (KE) & $91.3 \pm 6.3^{*}$ & $88 \pm 14^{*}$ \\
\hline Knee flexion (KF) & $83.2 \pm 18.3$ & $78 \pm 23^{\star *}$ \\
\hline $\begin{array}{l}\text { Lateral hip rotation-knee extension } \\
\text { (LHR-KE) }\end{array}$ & $83.7 \pm 12.6^{\star \star *}$ & $74 \pm 21.5^{\star \star *}$ \\
\hline $\begin{array}{l}\text { Lateral hip rotation-knee flexion } \\
\text { (LHR-KF) }\end{array}$ & $78.2 \pm 17$ & $50.6 \pm 26.3$ \\
\hline
\end{tabular}

† For both gluteus maximus and semitendinosus muscles, the ROM corresponding to the peak of EMG activity was significantly greater for the KE exercises compared to those involving LHR-KE and LHR-KF; ¥ For both gluteus maximus and semitendinosus muscles, the ROM corresponding to the peak of muscular activity was significantly greater for the KF exercise compared to those involving LHR-KE and LHR-KF; * For both gluteus maximus and semitendinosus muscles, the percentage of the ROM corresponding to the peak of EMG activity was significantly greater for the KE exercises compared to those involving KF, LHR-KE and LHR-KF; ** For the semitendinosus muscle, the percentage of the ROM corresponding to the peak of EMG activity was significantly greater for the KF exercises compared to those involving LHR-KF; *** For both gluteus maximus and semitendinosus muscles, the percentage of the ROM corresponding to the peak of EMG activity was significantly greater for the LHR-KE exercises compared to those involving LHR-KF.

therapeutic exercises and found that those performed with $\mathrm{KF}$ and associated with LHR showed similar amounts of EMG activities for the gluteus maximus, suggesting that all modalities might be effective choices for activating the gluteus maximus. The exercises performed with KE showed the highest 
semitendinosus activity, indicating that it might be employed to activate the semitendinosus muscle.

The integrity of the gluteus maximus is important for the stability of the sacroiliac joint ${ }^{2,6,8,14}$, however, the effectiveness of neuromuscular training with exercises has been based on subjective perceptions ${ }^{21,22}$. Many studies have shown reduced activity of the gluteus maximus in low back pain patients ${ }^{4,16,23}$, but there is no consensus regarding the best exercises to stimulate this muscle. Knowledge of the intensity of muscular activation in prescribed exercises is essential for more effective therapeutic interventions.

The ROM corresponding to the peak of activity of the hip extensors during the exercises performed with $\mathrm{KE}$ was close to the end of the movement cycles, when compared to the other exercises. This finding demonstrates that this exercise may be selected when the rehabilitation goal is to increase muscular activation at the end of the ROM. The gluteus maximus is frequently weak and elongated due to activities of daily living and mainly to the great amount of time that the majority of the population remains seated during the day ${ }^{24}$.

When the exercises performed with $\mathrm{KE}$ were compared to other investigated exercises, it was observed that the semitendinosus had the highest EMG activity levels, whereas the gluteus maximus had the lowest. Even with the greater lever resistances during this exercise, it does not seem to be most recommended to specifically strengthen the gluteus maximus, but for the semitendinosus. One possible explanation is that during this movement, the hamstrings, as biarticular muscles, maintain adequate length-tension relationships because they were shortened at the hip and elongated at the knee joint, thus, optimizing its effects during this movement.

The exercises performed with KF showed the greatest activity for the gluteus maximus and lowest for the semitendinosus. Tassi and Engrácia-Valenti ${ }^{25}$ also found greater gluteus maximus activity during hip extension associated with the KF and erect trunk with the double-pulley assistance equipment, when compared with other hip, knee and trunk positions. In the current study, the gluteus maximus peaks of activity occurred at $83 \%$ of the movement cycle. This highest activity level was probably due to the fact that, during these exercises, the hamstrings were in active insufficiency and their capacity to produce or maintain active tension was diminished. Worrell et al. ${ }^{19}$ observed increases in gluteus maximus activity during exercises performed with $\mathrm{KF}$ at $30^{\circ}$ and $60^{\circ}$ when compared to $90^{\circ}$. In the present study, the peak activity of the gluteus maximus occurred close to the end of the movement. It is possible that during active stretching, biarticular muscles may be actively ineffective in an anterior point at the end of a $\mathrm{ROM}^{15}$. Thus, the gluteus maximus would have to be more activated from this point to complete the movement. According to the present results, these exercises may be more effective choices if the objective is to specifically train the gluteus maximus.

When the exercises involved LHR-KE, the semitendinosus muscle showed moderate activities, which were lower than the ones performed with KE, but higher than those involving LHR-KF, which showed the lowest activity. However, the gluteus maximus was similarly activated during both exercises and no significant differences were found when compared with exercises performed with KF, indicating that all of three modalities could be good choices to stimulate this muscle. The combination of movements involving LHR-KF, might have forced the gluteus maximus to function in a shorter position, recruiting more motor units to meet two simultaneous demands and associated with the active insufficiency of the hamstrings, probably made the LHRKF exercises most effective to specifically activate the gluteus maximus.

It is interesting to note that the KE exercises showed the lowest gluteus maximus activation and the simple act of laterally rotating the hip considerably increased its activation. The LHR that the subject had to perform during the exercises probably increased the level of difficulty, reducing the achieved amplitudes. The ROM corresponding to the gluteus maximus peaks of activity was lower than that of the other exercises; however, when these values were normalized to other modalities, they also corresponded to $83 \%$ of the movement cycle for the LHR-KE and $78 \%$ for the LHR-KF. The hamstrings, as biarticular muscles, became actively inefficient before the end of the movement and associated with a monoarticular muscle that was also weak, probably caused the earlier peak of activity of the gluteus maximus. The semitendinosus peak activation occurred at $8^{\circ}$ (50\% of the movement cycle) for the LHR-KF exercises. This modality showed the lowest ROM, probably because of the difficulty in the accomplishment of the three combined movements.

No studies were found which analyzed the gluteus maximus activities during these exercise modalities. In other modalities, there are reports of gluteus maximus activations of $13.6 \%$ of MVIC for the diagonal hip and shoulder extension in four-point kneeling exercises and $9.75 \%$ for the back bridge, which demonstrated that these therapeutic exercises induced lower activation of this muscle ${ }^{21}$. However, Souza, Baker and Powers ${ }^{26}$ reported an activity level of $19.2 \%$ for the diagonal hip and shoulder extension in four-point kneeling exercises. Donatelli, Carp and Ekstrom ${ }^{27}$ found greater values for gluteus maximus activities during these exercises. They observed 56\% levels for diagonal hip and shoulder extension, $40 \%$ for the unilateral bridge, and $25 \%$ for the back bridge exercises. The differences between the present results could be due to the methods used to determine the MVIC (peak versus one-second window of activity). 
The current study found similar activity levels for the exercises performed with KF, LHRKE, and LHR-KF, demonstrating that they all could be effective options to strengthen the gluteus maximus. In these positions, the length-tension curves of the biarticular hamstring muscles are not in ideal positions to generate force. Oh et al. ${ }^{28}$ found increased gluteus maximus and medial hamstring activities and decreased anterior pelvic tilt during prone hip extension exercises with abdominal drawing-in maneuvers. Sahrmann ${ }^{24}$ suggested that the KE exercises should be performed during the initial treatment phases with the goal of training patients to initiate the motions with the gluteus maximus and to increase its participation while decreasing hamstring activities during hip extension. It was also suggested that the patients should perform a smooth LHR by contracting the gluteal muscles before initiating the extension movements and that the KF exercises should be later performed to improve the performance of the gluteus maximus muscle. One could argue the fact that the speed of the movements was not controlled and it is known that the magnitude of the EMG signals can be directly influenced by several factors, such as speed, acceleration, ROM, load, and practice. However, although movement speed was not controlled, the subjects were instructed to perform the movements at their natural speed in order to reproduce situations similar to those employed in clinical practice.
The results of this study were representative of a young, asymptomatic population. Studies involving subjects with low back pain or sacroiliac dysfunctions are needed, and these findings might be employed as references. It is important to point out that the present study evaluated only active exercises, in an open kinetic chain; thus, its external validity is limited to this situation. However, the results of this study formed a baseline for future studies which could evaluate the influences of external loads or muscle activity of exercise in various positions, within closed kinetic chains, or with different types of contractions.

\section{Conclusions : : :}

Exercises performed with KF or LHR or their combinations might be effective choices to optimize gluteus maximus functions. Both KF and LHR increased gluteus maximus and decreased semitendinosus activity. In contrast, the exercises performed with KE were shown to be appropriate choices to increase semitendinosus activity levels.

\section{Acknowledgments $: \therefore$.}

Brazilian Government Funding Agencies (CNPq/ FAPEMIG).

\section{References}

1. Cholewicki J, van Dieën JH, Arsenault AB. Muscle function and dysfunction in the spine. J Electromyogr Kinesiol. 2003;13(4):303-4.

2. Hungerford B, Gilleard W, Hodges P. Evidence of altered lumbopelvic muscle recruitment in the presence of sacroiliac joint pain. Spine. 2003;28(14):1593-600.

3. Jull GA, Janda V. Muscles and motor control in low back pain. In: Twomey LT, Taylor JR, editors. Physical therapy of the low back. New York: Churchill Livingstone; 1987. p. 253-78

4. Leinonen V, Kankaanpää $M$, Airaksinen 0 , Hänninen 0 . Back and hip extensor activities during trunk flexion/extension: effects of low back pain and rehabilitation. Arch Phys Med Rehabil. 2000;81(1):32-7.

5. Mooney V. Coupled motion of contralateral latissimus dorsi and gluteus maximus: its role in sacroiliac stabilization. In: Vleeming $A$, editor. Movement, stability \& low back pain: the essential role of the pelvis. London: Harcourt Publishers; 1999. p. 155-22.

6. Mooney V, Pozos R, Vleeming A, Gulick J, Swenski D. Exercise treatment for sacroiliac pain. Orthopedics. 2001;24(1):29-32.

7. Vogt $L$, Pfeifer K, Banzer W. Neuromuscular control of walking with chronic low-back pain. Man Ther. 2003;8(1):21-8.
8. Hossain M, Nokes LD. A model of dynamic sacro-iliac joint instability from malrecruitment of gluteus maximus and biceps femoris muscles resulting in low back pain. Med Hypotheses. 2005;65(2):278-81.

9. Pool-Goudzwaard AL, Vleeming A, Stoeckart R, Snidjers CJ, Mens JM Insufficient lumbopelvic stability: a clinical, anatomical and biomechanical approach to "a-specific" low back pain. Man Ther. 1998;3(1):12-20.

10. Snidjers CJ, Vleeming A, Stoeckart R. Transfer of lumbosacral load to iliac bones and legs. Part 1: biomechanics of selfbracing of the sacroiliac joint and its significance for treatment and exercise. Clin Biomech. 1993:8:285-94.

11. Vleeming A, Pool-Goudzwaard AL, Hammudoghlu D, Stoeckart R, Snidjers CJ, Mens JM. The function of the long dorsal sacroiliac ligament: its implication for understanding low back pain. Spine. 1996;21(5):556-62

12. van Wingerden JP, Vleeming A, Buyruk HM, Raissadat K. Stabilization of the sacroiliac joint in vivo: verification of muscular contribution to force closure of the pelvis. Eur Spine J. 2004;13(3):199-205.

13. Clark BC, Manini TM, Mayer JM, Ploutz-Snyder LL, Graves JE. Electromyographic activity of the lumbar and hip extensors during dynamic trunk extension exercise. Arch Phys Med Rehabil. 2002;83(1):1547-52. 
14. Vleeming A, Pool-Goudzwaard AL, Stoeckart R, van Wingerden JP, Snijders CJ. The posterior layer of the thoracolumbar fascia. Its function in load transfer from spine to legs. Spine. 1995;20(7):753-8.

15. Lehman GJ, Lennon D, Tresidder B, Rayfield B, Poschar M. Muscle recruitment patterns during the prone leg extension. BMC Musculoskelet Disord. 2004;5:3.

16. VogtL, BanzerW. Dynamictesting of the motor stereotype in pronehip extension from neutral position. Clin Biomech (Bristol, Avon). 1997;12(2):122-7.

17. Cram JR, Kasman GS, Holtz J. Introduction to surface electromyography. Maryland: Aspen Publishers; 1998.

18. Merletti R. Standards for reporting EMG data. J Electromyogr Kinesiol. 1999;9(1):3-4.

19. Worrell TW, Karst G, Adamczyk D, Moore R, Stamley C, Steimel B, et al. Influence of joint position on electromyography and torque generation during maximal isometric voluntary contractions of the hamstrings and gluteus maximus muscles. J Orthop Sports Phys Ther. 2001;31(12):730-40.

20. Sakamoto AC, Teixeira-Salmela LF, de Paula-Goulart FR, de Morais Faria $\mathrm{CDC}$, Guimarães $\mathrm{CQ}$. Muscular activation patterns during active prone hip extension exercises. J Electromyogr Kinesiol. 2008;19(1):105-12.

21. Konrad DP, Schmitz K, Denner A. Neuromuscular evaluation of trunktraining exercises. J Athl Train. 2001;36(2):109-18.
22. McGill SM. Low back exercises: evidence for improving exercise regimens. Phys Ther. 1998;78(7):754-65.

23. Kankaanpää M, Taimela S, Laaksonen D, Hänninen O, Airaksinen O. Back and hip extensor fatigability in chronic low back pain patients and controls. Arch Phys Med Rehabil. 1998;79(4):412-7.

24. Sahrmann SA. Diagnosis and treatment of movement impairment syndromes. St Louis: Mosby; 2002.

25. Tassi N, Engracia Valenti V. Electromyographic evaluation of movements of lower limb in double pulley system equipment: comparison between gastrocnemius (caput laterale) and gluteus maximus. Electromyogr Clin Neurophysiol. 2007;47(6):293-9.

26. Souza GM, Baker LL, Powers CM. Electromyographic activity of selected trunk muscles during dynamic spine stabilization exercises. Arch Phys Med Rehabil. 2001;82(11):1551-7.

27. Donatelli RA, Carp KC, Ekstrom RA. Electromyographic analysis of core trunk, hip, and thigh muscles during 9 rehabilitation exercises. J Orthop Sports Phys Ther. 2007;37(12):754-62.

28. Oh JS, Cynn HS, Won JH, Kwon OY, Yi CH. Effects of performing an abdominal drawingin maneuver during prone hip extension exercises on hip and back extensor muscle activity and amount of anterior pelvic tilt. J Orthop Sports Phys Ther. 2007;37(6):320-4. 